\title{
Article \\ Thermal Effects on Surface and Subsurface Modifications in Laser-Combined Deep Rolling
}

\author{
Robert Zmich ${ }^{1,2, *}$ and Daniel Meyer ${ }^{1,2}$ (D) \\ 1 Leibniz Institute for Materials Engineering IWT, Badgasteiner Str. 3, 28359 Bremen, Germany; \\ dmeyer@iwt-bremen.de \\ 2 Faculty of Production Engineering, University of Bremen and MAPEX Center for Materials and Processes, \\ Bibliothekstr 1, 28359 Bremen, Germany \\ * Correspondence: zmich@iwt-bremen.de; Tel.: +49-421-218-51148
}

check for updates

Citation: Zmich, R.; Meyer, D.

Thermal Effects on Surface and Subsurface Modifications in Laser-Combined Deep Rolling. J. Manuf. Mater. Process. 2021, 5, 55. https://doi.org/10.3390/jmmp 5020055

Academic Editor: Johan Berglund

Received: 27 April 2021

Accepted: 21 May 2021

Published: 28 May 2021

Publisher's Note: MDPI stays neutral with regard to jurisdictional claims in published maps and institutional affiliations.

Copyright: (c) 2021 by the authors. Licensee MDPI, Basel, Switzerland. This article is an open access article distributed under the terms and conditions of the Creative Commons Attribution (CC BY) license (https:// creativecommons.org/licenses/by/ $4.0 /)$.

\begin{abstract}
Knowledge of the relationships between thermomechanical process loads and the resulting modifications in the surface layer enables targeted adjustments of the required surface integrity independent of the manufacturing process. In various processes with thermomechanical impact, thermal and mechanical loads act simultaneously and affect each other. Thus, the effects on the modifications are interdependent. To gain a better understanding of the interactions of the two loads, it is necessary to vary thermal and mechanical loads independently. A new process of laser-combined deep rolling can fulfil exactly this requirement. The presented findings demonstrate that thermal loads can support the generation of residual compressive stresses to a certain extent. If the thermal loads are increased further, this has a negative effect on the surface layer and the residual stresses are shifted in the direction of tension. The results show the optimum range of thermal loads to further increase the compressive residual stresses in the surface layer and allow to gain a better understanding of the interactions between thermal and mechanical loads.
\end{abstract}

Keywords: deep rolling; laser treatment; residual stresses; process signatures

\section{Introduction}

It is well known that during thermomechanical processes, a wide range of surface modifications result and affect the surface integrity [1]. In order to make a prediction concerning the functional properties of a workpiece, it is necessary to understand the relationships between the loads and the resulting material modifications. The loads can occur individually and in combination [2]. These relationships can be determined via changes in state variables and described in models. In the future, it should be possible to adjust the required surface integrity by a targeted selection of the manufacturing process and its process parameters. This solution to the inverse problem is gaining more and more attention in both, academics and industry. Load-oriented approaches to predict the resulting surface integrity of manufacturing processes instead of process parameter-based approaches are currently presented e.g., by Brinksmeier et al. [2]. The innovative approach of the so-called Process Signatures should make it possible to draw conclusions about the resulting modifications independently of the manufacturing process and only by means of internal material loads prevailing in the workpiece [3,4].

For example, Kämmler et al. have developed a Process Signature component for the deep rolling process [5]. The internal material loads were analysed based on the Hertzian contact conditions and the modifications considered were the residual stress change at the surface. In addition, Frerichs et al. managed to establish a Process Signature component for processes with thermal load. It was found that the maximum temperature gradient is appropriate to describe the resulting residual stresses [6].

For a better understanding of the modifications induced by thermomechanical processes, it is necessary to be able to adjust the two acting loads independently. For most 
thermomechanical processes this is not possible, because the change of one process variable leads to a change of the thermal and mechanical load at the same time. Independent variation of the loads is possible with the newly introduced laser-combined deep rolling process [7]. Here, the laser couples the thermal loads into the workpiece. Deep rolling is used in this process as it offers the possibility to introduce mechanical loads into the workpiece $[8,9]$. By combining these processes, it is possible to vary both loads independently of each other and thus to consider the interactions in a targeted manner.

A large amount of research has already been carried out on laser-assisted processes. However, the focus of these works was mostly on the optimization of the process, the reduction of tool wear or the increase of the lifetime of the processed workpieces [10-16]. The fundamental consideration of how thermal and mechanical loads interact has not been fully investigated to date. Studies by Maier used the process of laser-combined deep rolling to prove that the consideration of thermal loads during grinding is sufficient to make a prediction of the structural changes in the subsurface layers [17]. The investigations show that the mechanical loads have no influence on the formation of new microstructural changes.

In his work, Cherif was able to demonstrate the positive influence of deep rolling at elevated temperatures on the stability of the residual stresses. With these more stable residual stresses, he shows an increase in life under alternating load [18]. In this case, the workpieces were heated by induction heating and the temperature was kept constant. In thermomechanical processes, however, there is always a heat source that moves over the workpiece surface and thus high temperature gradients are acting during the processes. The correlation of different temperature gradients, which are realized by laser heating, with varying mechanical loads and the achievable modifications are examined in detail for the first time in this paper.

\section{Materials and Methods}

\subsection{Material, Heat Treatment, and Specimen Geometry}

The investigations were performed with the material AISI 4140 (42CrMo4). The analysed material is well studied and comprehensive data (including common thermal and mechanical properties of this steel) also from other publications are available [19]. Furthermore, publications aiming specifically at the generation of process signatures mainly use an AISI4140. For a better transferability comparable heat treatment condition were chosen. In addition, this steel is used for highly stressed components, where the combination of high strength and wear resistance with toughness is especially important. The chemical composition of the material is shown in Table 1. Cylindrical specimens were heat treated including austenitizing at $850^{\circ} \mathrm{C}$ for $2 \mathrm{~h}$, oil quenching to $60^{\circ} \mathrm{C}$, and tempering at $400{ }^{\circ} \mathrm{C}$ for $4 \mathrm{~h}$. The diameter of the specimens before pre-machining was $58 \mathrm{~mm}$. Prior to deep rolling, the workpieces were turned to a diameter of $57.5 \mathrm{~mm}$ with a depth of cut of $a_{p}=0.4 \mathrm{~mm}$, a feed of $f=0.2 \mathrm{~mm}$, and a cutting speed of $v_{c}=900 \mathrm{~m} / \mathrm{min}$. The length of the specimen was $100 \mathrm{~mm}$.

Table 1. Composition of AISI 4140 in weight percent.

\begin{tabular}{ccccccc}
\hline Notation & $\mathbf{C}$ & $\mathbf{C r}$ & Ni & Mo & Si & Mn \\
\hline $\begin{array}{l}\text { AISI } 4140 \\
\text { 42CrMo4 }\end{array}$ & 0.43 & 1.09 & - & 0.25 & 0.26 & 0.74 \\
\hline
\end{tabular}

\subsection{Experimental Setup and Analysis}

The deep rolling process, which realizes the mechanical load in this process, was performed using a mechanically supported deep rolling tool from Ecoroll AG Werkzeugtechnik. The diameter of the roll was $55 \mathrm{~mm}$ with a rounding radius of $1 \mathrm{~mm}$ and a tilt angle of $1.5^{\circ}$. The thermal load was applied to the workpiece using a $12 \mathrm{~kW}$ disk laser from Trumpf. The wavelength of the laser was $1030 \mathrm{~nm}$. It was applied to the workpiece surface using a line optic (width $0.5 \mathrm{~mm}$ perpendicular to rolling direction; length $10 \mathrm{~mm}$ parallel to rolling 
direction) and a robot arm. During processing, oxidation, which would affect the coupling of the laser and the measurement of the surface temperature, was prevented by supplying inert gas. Figure 1 shows the experimental setup.

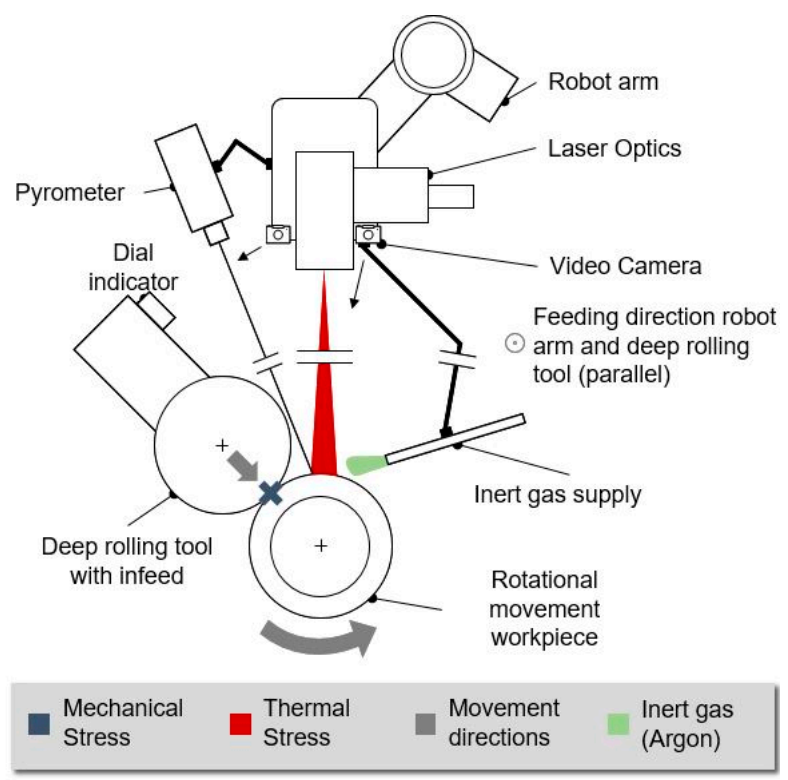

Figure 1. Schematic experimental setup for laser-combined deep rolling.

The deep rolling force was measured via an analogue gauge integrated in the deep rolling tool EG45, which recorded the deflection of the tool and was able to indicate the deep rolling force by means of a defined spring characteristic. By using a Metis M3 22 quotient pyrometer from SensoTherm $\mathrm{GmbH}$, it was possible to measure the surface temperature on the reflective workpiece surface in a range of $350-1300{ }^{\circ} \mathrm{C}$ without contact.

In order to record the influence of the thermal load on the modifications during thermomechanical processing, four different laser powers were selected at three fixed deep rolling forces. Table 2 lists the individual parameters.

Table 2. Parameters for laser-combined deep rolling process.

\begin{tabular}{ccccc}
\hline No. & $\begin{array}{c}\text { Deep Rolling } \\
\text { Force } \mathbf{F}_{\mathbf{r}}\end{array}$ & Laser Power $\mathbf{P}_{\mathbf{L}}$ & $\begin{array}{c}\text { Circumferential Speed } \\
\text { of the Workpiece } \mathbf{v}_{\mathbf{c w}}\end{array}$ & Feed $\mathbf{f}$ \\
\hline 1 & $900 \mathrm{~N}$ & $0 / 240 / 380 / 550 / 725 \mathrm{~W}$ & $7.28 \mathrm{~m} / \mathrm{min}$ & $0.4 \mathrm{~mm}$ \\
2 & $1600 \mathrm{~N}$ & $0 / 240 / 380 / 550 / 725 \mathrm{~W}$ & $7.28 \mathrm{~m} / \mathrm{min}$ & $0.4 \mathrm{~mm}$ \\
3 & $3000 \mathrm{~N}$ & $0 / 240 / 380 / 550 / 725 \mathrm{~W}$ & $7.28 \mathrm{~m} / \mathrm{min}$ & $0.4 \mathrm{~mm}$ \\
\hline
\end{tabular}

Each experiment was carried out in such a way that a deep rolled track width of $10 \mathrm{~mm}$ was achieved. This ensured that no edge effects could falsify the subsequent measurement of the residual stresses, performed in the center of the tracks.

To determine the required maximum temperature gradients, a numerical simulation of the temperature fields was performed. The software Sysweld from ESI Group's and the model of the moving heat source with an area of $5 \mathrm{~mm}^{2}$ was used. The 3D simulation was carried out with a total of 10800 3D elements with 8 Gaussian points each. The dimension in the depth is $33 \mu \mathrm{m}$ and on the surface $27 \mu \mathrm{m}$. The entire mesh consists of a total of 12348 nodes. The simulated element is $30 \mathrm{~mm}$ long, $10 \mathrm{~mm}$ deep and $5 \mathrm{~mm}$ wide. In addition, the mirror symmetry with regard to the axis was used. The value of $44 \%$ was set as the coefficient of coupling for the laser. The resulting maximum temperature gradient perpendicular to the workpiece surface and the corresponding maximum surface temperatures for the individual laser powers which were recorded during the process using the quotient pyrometer are listed in the Table 3. However, due to the spatial distance 
between the contact zones of the laser and the deep rolling tool, this maximum surface temperature is not exactly the temperature of the surface under the deep rolling tool but rather the maximum effective temperature during the entire process.

Table 3. Maximum temperature gradient and surface temperature for all laser power.

\begin{tabular}{ccc}
\hline Laser Power L & $\begin{array}{r}\text { Max. Surface Temperature } \\
\mathbf{T}_{\text {S, } \max }\end{array}$ & $\begin{array}{c}\text { Max. Temperature Gradient } \\
(\partial \mathrm{T} / \partial \mathbf{z})_{\max }\end{array}$ \\
\hline $240 \mathrm{~W}$ & $330^{\circ} \mathrm{C}$ & $740 \mathrm{~K} / \mathrm{mm}$ \\
$380 \mathrm{~W}$ & $450{ }^{\circ} \mathrm{C}$ & $1040 \mathrm{~K} / \mathrm{mm}$ \\
$550 \mathrm{~W}$ & $600^{\circ} \mathrm{C}$ & $1495 \mathrm{~K} / \mathrm{mm}$ \\
$725 \mathrm{~W}$ & $750{ }^{\circ} \mathrm{C}$ & $2230 \mathrm{~K} / \mathrm{mm}$ \\
\hline
\end{tabular}

The roughness measurements (ISO 25178) were carried out with the tactile roughness measuring device Surftest SV-3200 (Mitutoyo Deutschland GmbH, Neuss, Germany). The control of the measuring system and evaluation was performed with the software "Formtracepeak V5". A probe with a radius of $2 \mu \mathrm{m}$ and a tip angle of $60^{\circ}$ was used to determine the roughness.

For metallographic analysis, individual sections were eroded from the processed area and embedded for preparation. These were then ground and polished. The contrast after etching with $3 \%$ alk. nitric acid makes a potential microstructural transition visible.

The $\mathrm{X}$-ray tensiometric residual stress measurements were performed with a computercontrolled five-circle theta-2theta diffractometer Seifert XRD MZ VI E from GE Inspection Technology using a vanadium-filtered $\mathrm{Cr}-\mathrm{K} \alpha \mathrm{X}$-ray $(\lambda=0.2291 \mathrm{~nm})$. A primary beam objective with a diameter of $2 \mathrm{~mm}$ and a linear position-sensitive detector of the type Meteor 1D were used for the measurements. The $\sin ^{2} \Psi$ method was used to determine the residual stresses perpendicular and parallel to the rolling direction [20]. The X-Ray elastic constans $E=220,000$ MPa and $v=0.28$ were used to determine the stress under the assumption of normal stress being $\sigma_{\mathrm{zz}}=0 \mathrm{MPa}$ [19]. In order to record residual stress profiles, the required thickness was removed without any additional load with the help of an electrolyte of phosphoric and nitric acid after a successful measurement. After the removal, the residual stresses that had previously existed at the given depths are revealed on the new surface. This technique ensures that no additional loads influence the residual stresses.

\section{Results}

\subsection{Surface Topography}

The combination of thermal load and mechanical impact is expected to influence the deformation and thus the smoothing of the surface. After pre-machining by turning, the initial roughness was $\mathrm{Ra}=1.95 \mu \mathrm{m} \& \mathrm{Rz}=7.85 \mu \mathrm{m}$. The roughness ( $\mathrm{Ra}$ and $\mathrm{Rz}$ ) achieved at different temperatures and deep rolling forces are shown in Figure 2, which can also be found in Supplementary Material Roughness Data. It can be seen that the deep rolling force has a significant influence on the roughness. Thus, the roughness is reduced the most at the highest deep rolling force. With increased laser power or surface temperature, further reduction is observed. However, this effect is not as significant as with the variation of the deep rolling force. 


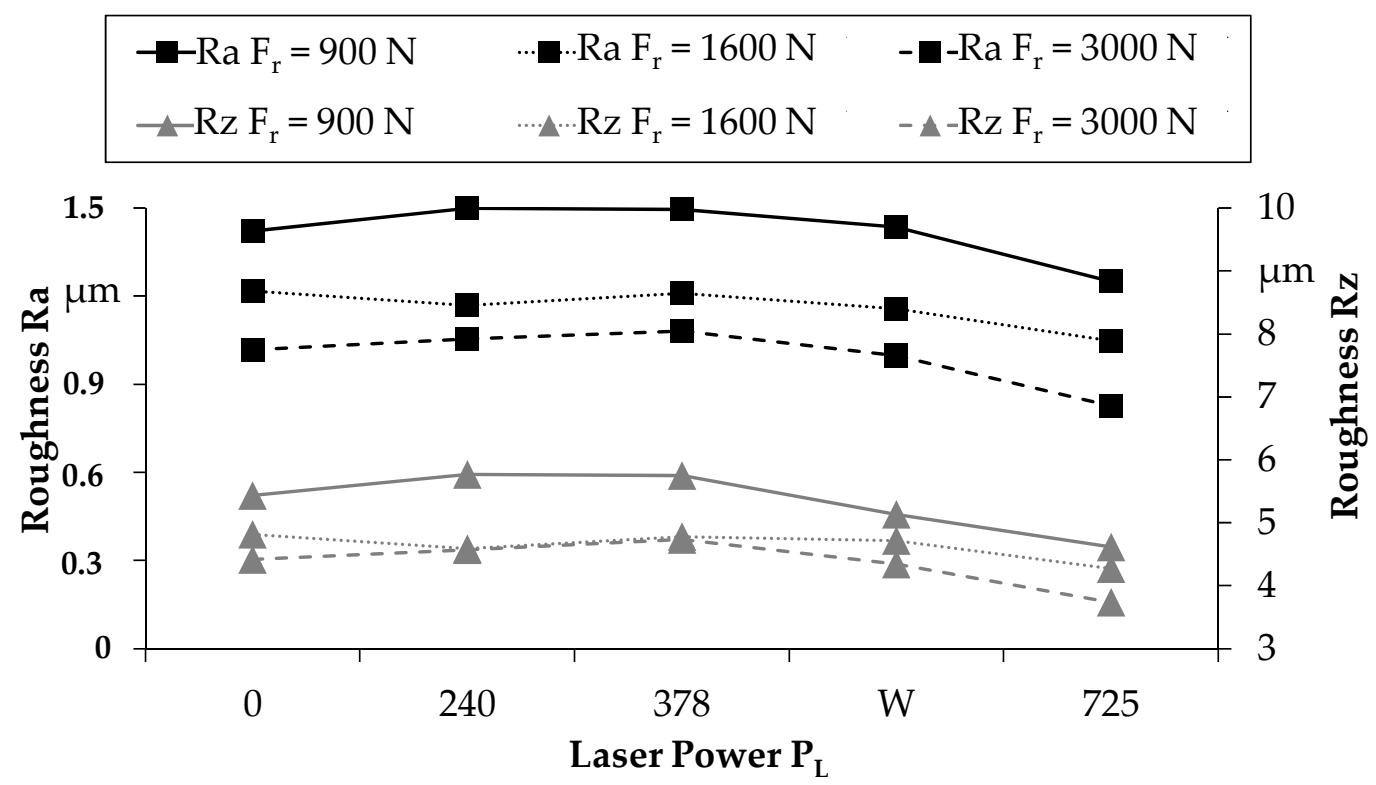

Figure 2. Roughness of samples with different thermomechanical loadings.

\subsection{Microstructure}

Besides the topography, the combinations of thermal and mechanical loads may affect the microstructure in the layers beneath the surface in different ways. The surface layers of the individual specimens, which were treated with varied thermomechanical loads were showed in Figure 3.

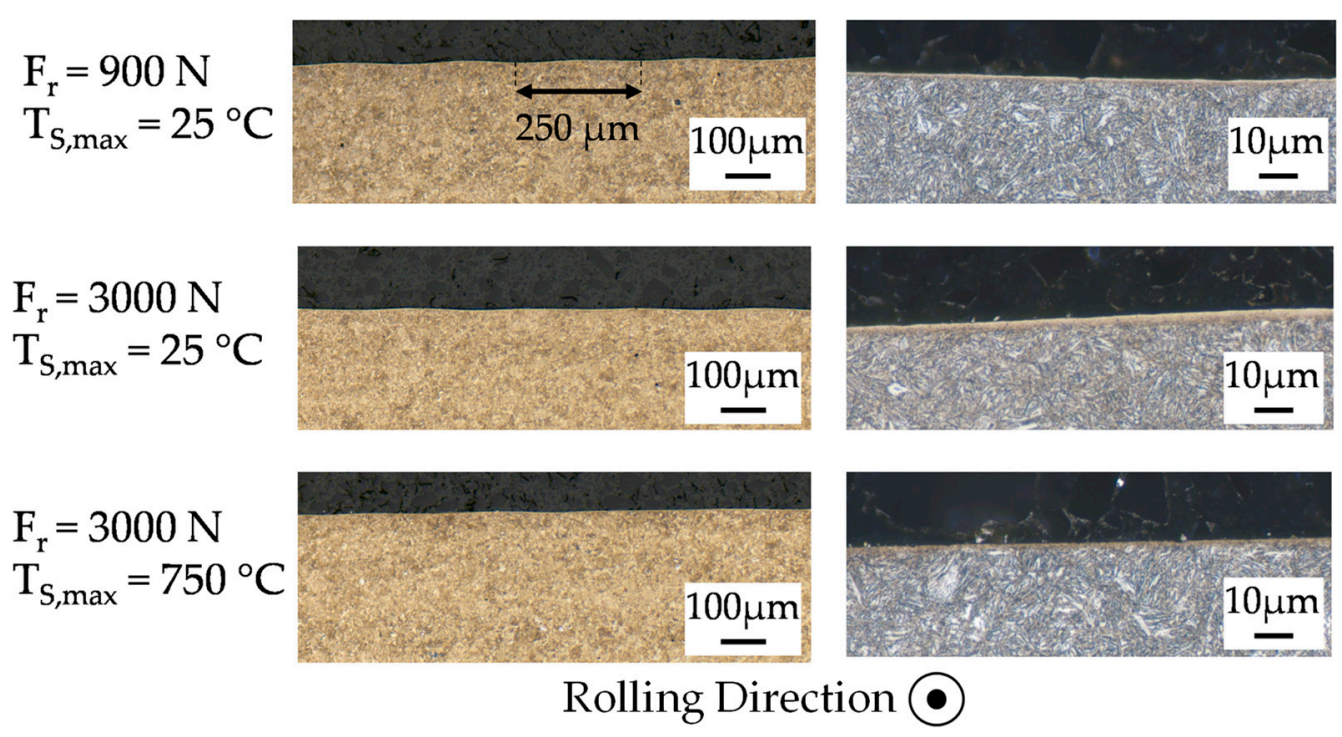

Figure 3. Metallographic cross-sections of the surface layer with different thermomechanical loads.

Remaining peaks and valleys from the turning process $\left(f_{t}=250 \mu \mathrm{m}\right)$ are still visible at $F_{r}=900 \mathrm{~N}$, whereas the deep rolling process at $F_{r}=3000 \mathrm{~N}$ has smoothed them out. Considering the larger scale of magnification, a white layer, which has a thickness of a few $\mu \mathrm{m}$, is visible in all experiments. Since this layer appears even in tests without laser machining, it can be assumed that the turning operation applied a corresponding thermal load. The effect of further smoothing of the roughness peaks with simultaneous thermal application is not observed. The comparison of the test with the lowest $\left(\mathrm{F}_{\mathrm{r}}=900 \mathrm{~N}\right.$; $\left.\mathrm{T}_{\mathrm{S}, \max }=25^{\circ} \mathrm{C}\right)$ and the highest $\left(\mathrm{F}_{\mathrm{r}}=3000 \mathrm{~N} ; \mathrm{T}_{\mathrm{S}, \max }=750^{\circ} \mathrm{C}\right)$ thermomechanical loads illus- 
trates that no microstructural changes occur on the microstructure level due to differently applied thermomechanical loads.

\subsection{Residual Stresses}

Residual stresses are a result of the plastic deformation within the surface and subsurface layers. The deformation is expected to be dependent of the applied mechanical load and also the temperature. The residual stress depth profiles of the experiments, which can also be found in the Supplementary Material Residual Stress Data, with different deep rolling forces and different temperatures are shown in Figure 4 (900 N deep rolling force) and Figure 5 (3000 N deep rolling force). The surface residual stresses measured in the rolling direction show a typical trend that occurs during a conventional thermal surface treatment. As the surface temperature is increased, the surface residual stresses are shifted more and more in the tensile region. When the experiment is performed with a constant deep rolling force of $900 \mathrm{~N}$ and no use of the laser, compressive residual stresses of $-440 \mathrm{MPa}$ occur at the surface. The maximum surface temperature of $750{ }^{\circ} \mathrm{C}$ at the same deep rolling force leads to tensile residual stresses of $900 \mathrm{MPa}$ at the surface. The highest compressive residual stresses are obtained at $50 \mu \mathrm{m}$ below the surface for all the lower deep rolling forces. The same trend is obtained for a higher rolling force of $3000 \mathrm{~N}$ deep rolling force. For conventional deep rolling without temperature increase by the laser, residual stresses of $-400 \mathrm{MPa}$ appear at the surface and $540 \mathrm{MPa}$ at the highest temperature. The depth of the maximum residual compressive stresses with the use of a temperature of $25^{\circ} \mathrm{C}, 330^{\circ} \mathrm{C}$, and $450^{\circ} \mathrm{C}$ on the surface occurring in this case is $\mathrm{z}=70 \mu \mathrm{m}$. With increasing the temperature the maximum residual compressive stresses occur in $\mathrm{z}=350 \mu \mathrm{m}$.

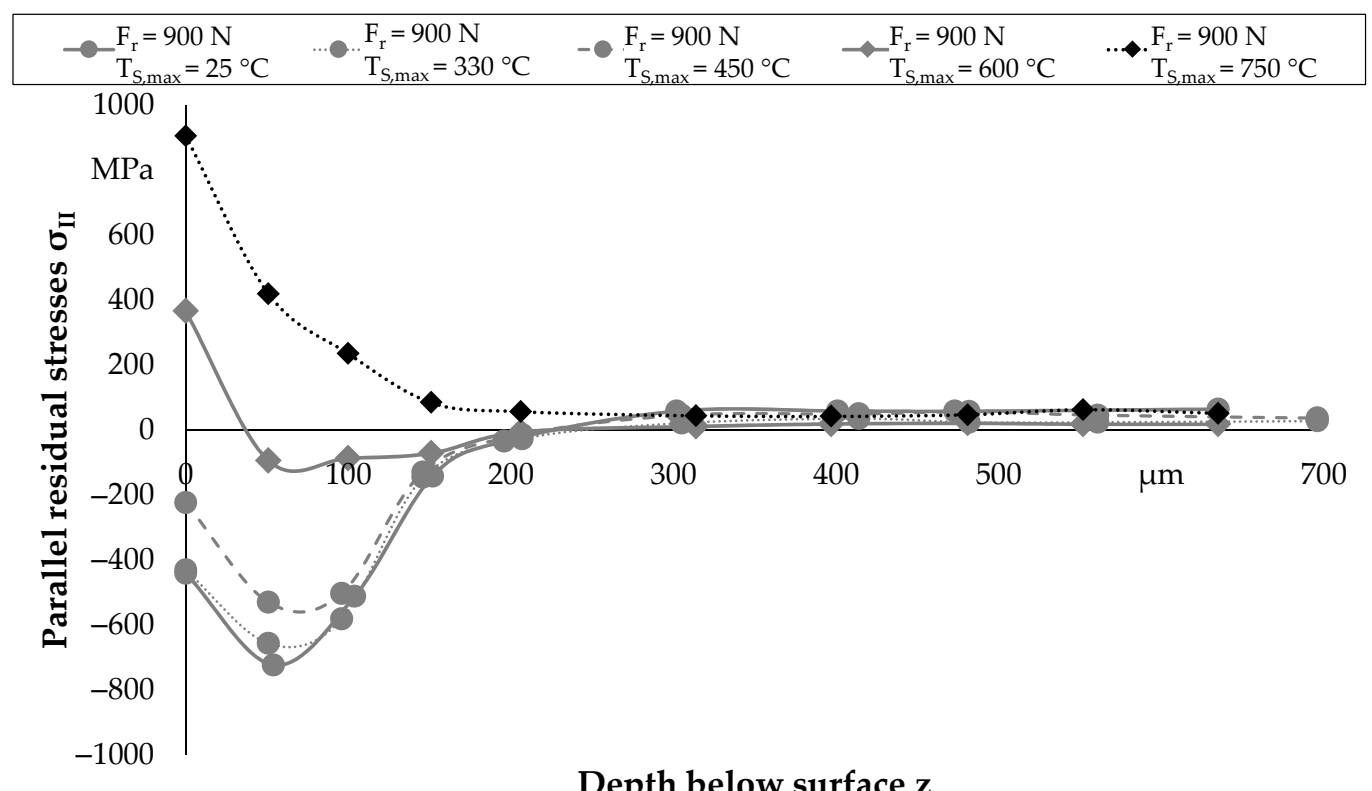

\section{Depth below surface $\mathrm{z}$}

Figure 4. residual stress depth distribution parallel to the rolling direction for $\mathrm{T}_{\mathrm{S}, \max }=25^{\circ} \mathrm{C}, 330^{\circ} \mathrm{C}, 450{ }^{\circ} \mathrm{C}, 600{ }^{\circ} \mathrm{C}$ and $750{ }^{\circ} \mathrm{C}$ with the deep rolling force $\mathrm{F}_{\mathrm{r}}=900 \mathrm{~N}$. 


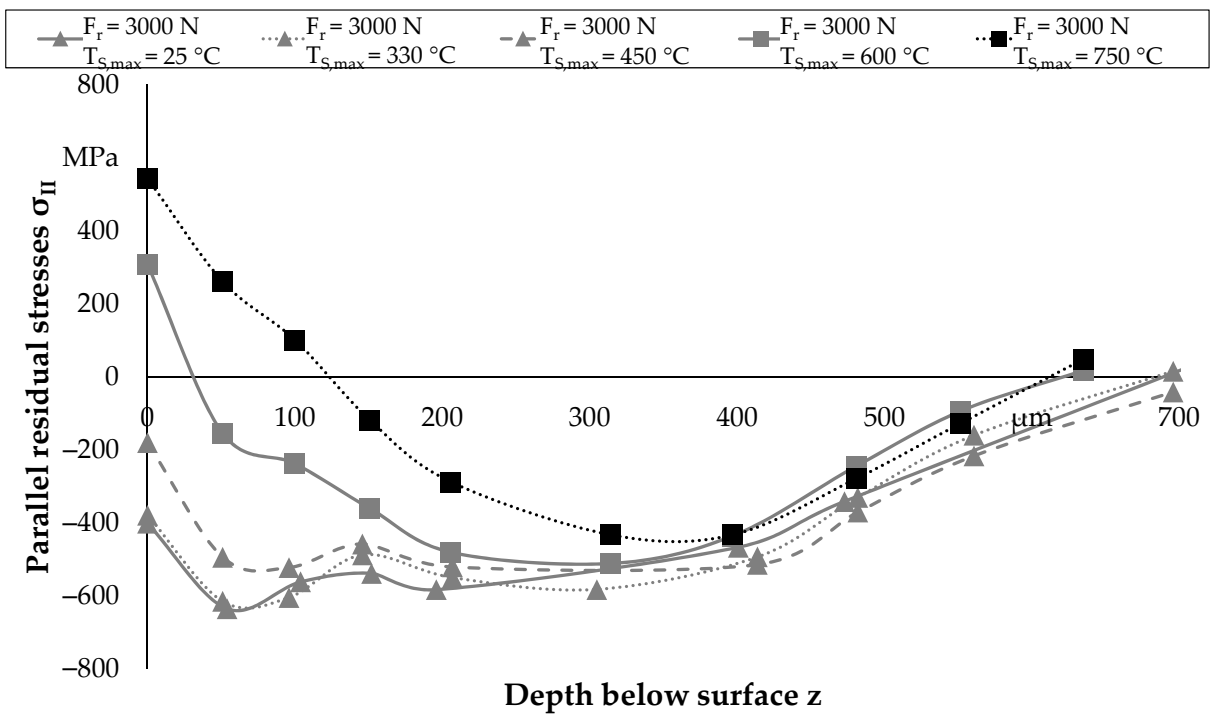

Figure 5. residual stress depth distribution parallel to the rolling direction for $\mathrm{T}_{\mathrm{S}, \max }=25^{\circ} \mathrm{C}, 330{ }^{\circ} \mathrm{C}, 450{ }^{\circ} \mathrm{C}, 600{ }^{\circ} \mathrm{C}$ and $750{ }^{\circ} \mathrm{C}$ with the deep rolling force $\mathrm{F}_{\mathrm{r}}=3000 \mathrm{~N}$.

Figures 6 and 7, also available in Supplementary Material Residual Stress Data, show the residual stress depth profiles perpendicular to the rolling direction with different thermal loads and the same mechanical forces as in Figures 4 and 5. It is evident that in both cases, up to a maximum surface temperature of $330{ }^{\circ} \mathrm{C}$ there is an enhancing effect in the introduction of compressive residual stresses due to the mechanical loads. At a deep rolling force of $900 \mathrm{~N}$, an increase from $-270 \mathrm{MPa}$ to $-390 \mathrm{MPa}$ is observed. At a deep rolling force of $3000 \mathrm{~N}$, the effect is less significant, resulting in a smaller increase from $-150 \mathrm{MPa}$ to $-190 \mathrm{MPa}$ (Figure 7). As in the work of [14,18], a further increase in temperature above $330{ }^{\circ} \mathrm{C}$ shows a negative influence on the development of residual stresses, which shifts the entire residual stress profile in the tensile direction. The depth of the maximum compressive residual stresses occurring is not changed by the thermal component and occurs at $\mathrm{z}=50 \mu \mathrm{m}\left(\mathrm{F}_{\mathrm{r}}=900 \mathrm{~N}\right)$ and $\mathrm{z}=300 \mu \mathrm{m}\left(\mathrm{F}_{\mathrm{r}}=3000 \mathrm{~N}\right)$ for all thermal loads.

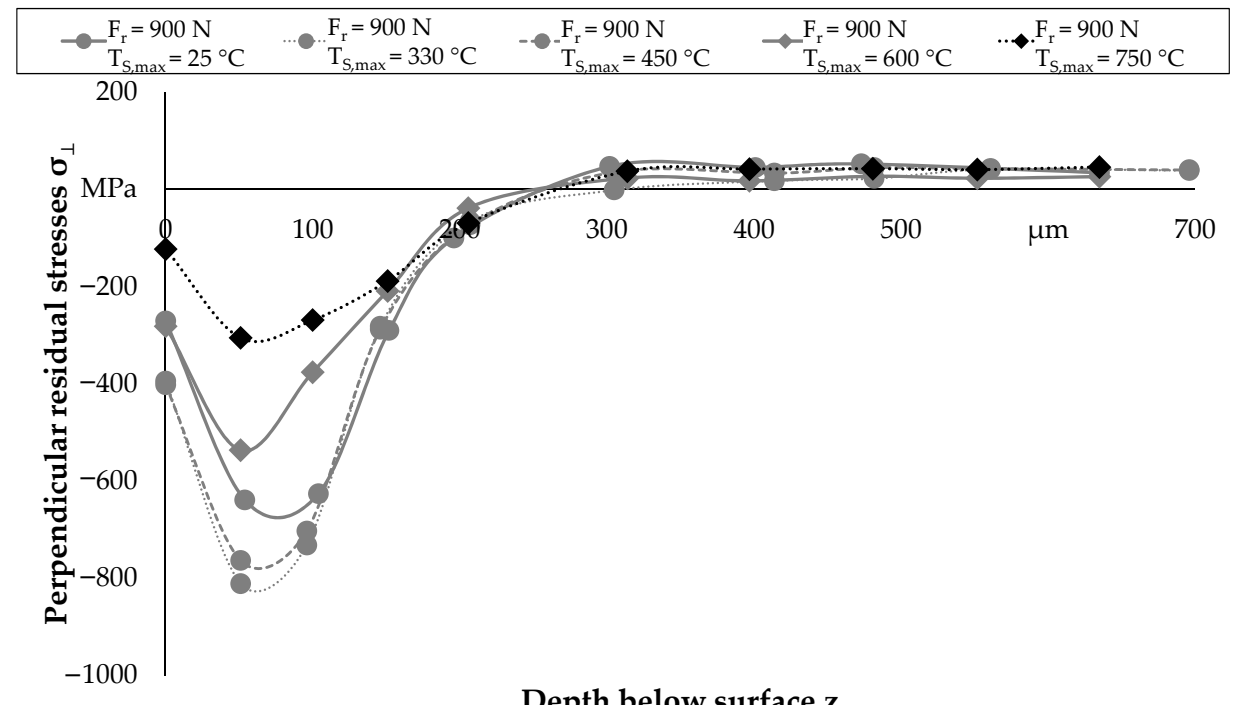

Depth below surface z

Figure 6. residual stress depth distribution perpendicular to the rolling direction for $\mathrm{T}_{\mathrm{S}, \max }=25^{\circ} \mathrm{C}, 330^{\circ} \mathrm{C}, 450{ }^{\circ} \mathrm{C}, 600{ }^{\circ} \mathrm{C}$ and $750{ }^{\circ} \mathrm{C}$ with the deep rolling force $\mathrm{F}_{\mathrm{r}}=900 \mathrm{~N}$. 


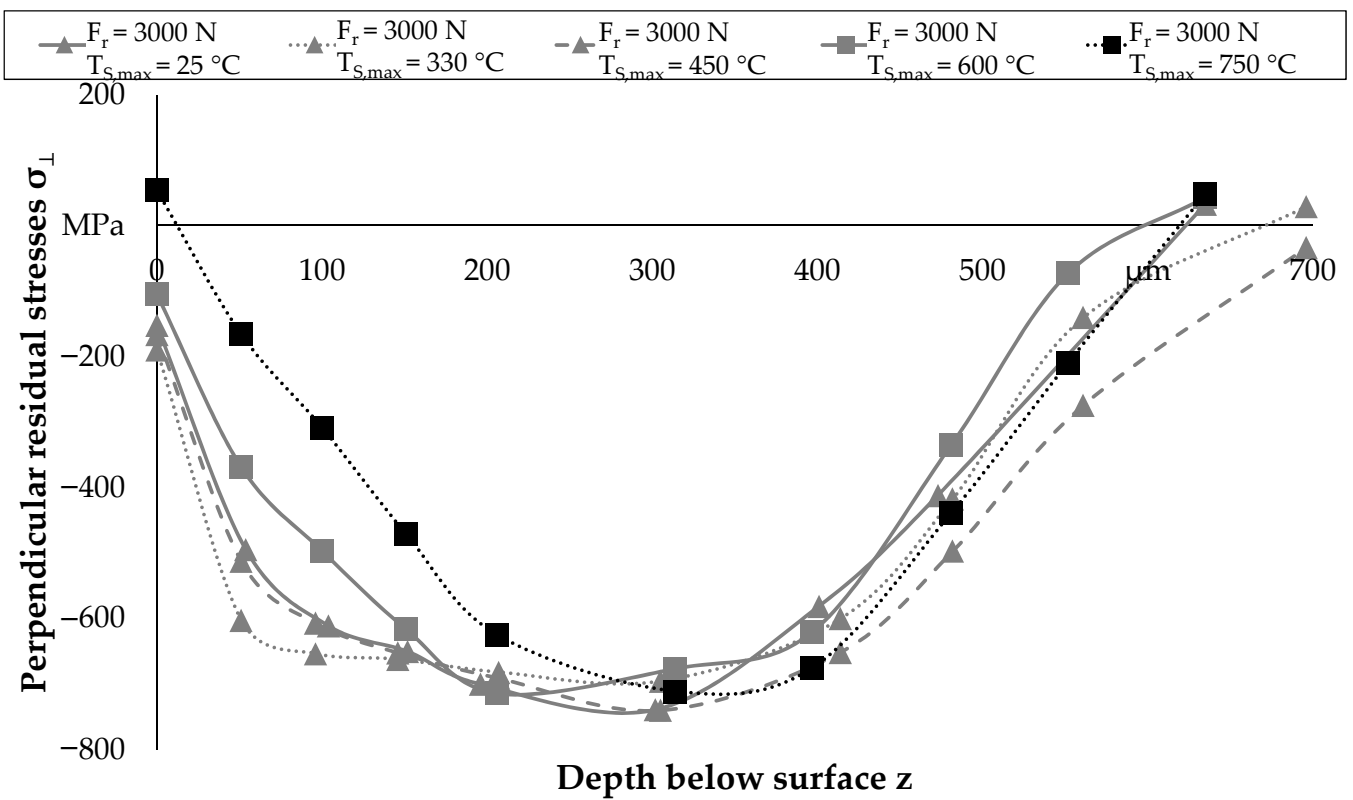

Figure 7. residual stress depth distribution perpendicular to the rolling direction for $\mathrm{T}_{\mathrm{S}, \max }=25^{\circ} \mathrm{C}, 330^{\circ} \mathrm{C}, 450{ }^{\circ} \mathrm{C}, 600{ }^{\circ} \mathrm{C}$ and $750{ }^{\circ} \mathrm{C}$ with the deep rolling force $\mathrm{F}_{\mathrm{r}}=3000 \mathrm{~N}$.

\section{Discussion}

Consideration of the roughness may indicate that the main influence on the surface and subsurface is the mechanical load. However, it can be observed that with increase of the thermal component the roughness can be further improved. This can be attributed to the reduction of the yield strength, which allows the mechanical load to cause a higher plastic deformation, thus further smoothing the roughness peaks.

The experiments presented in this paper have not produced any significant changes of the microstructure at any of the different applied thermomechanical loads. It is assumed that the maximum temperature gradients were too high to generate required temperatures sufficient amount of time to cause thermally induced microstructural changes.

When considering the residual stress depth profiles, it becomes clear that different effects occur for residual stresses in the parallel and perpendicular direction. Residual stresses parallel to the rolling direction are influenced by thermal effects in a more pronounced way. As the temperature increases, the thermally induced relaxation of the stress state in the workpiece is increased and the residual stresses are shifted to the tensile regions. This can be explained by the way of application of the laser power into the workpiece. The laser optics have a length in the parallel direction of $1=10 \mathrm{~mm}$ and a width in the perpendicular direction of $b=0.5 \mathrm{~mm}$. The simulation of the laser process shown in Figure 8 with the dimensions of the laser optics used in this work confirm this assumption. The sensitivity of the residual stresses parallel to the rolling direction to thermal influences is much higher than perpendicular to them and thermal relaxation effects predominate over mechanically induced plastic deformation. 


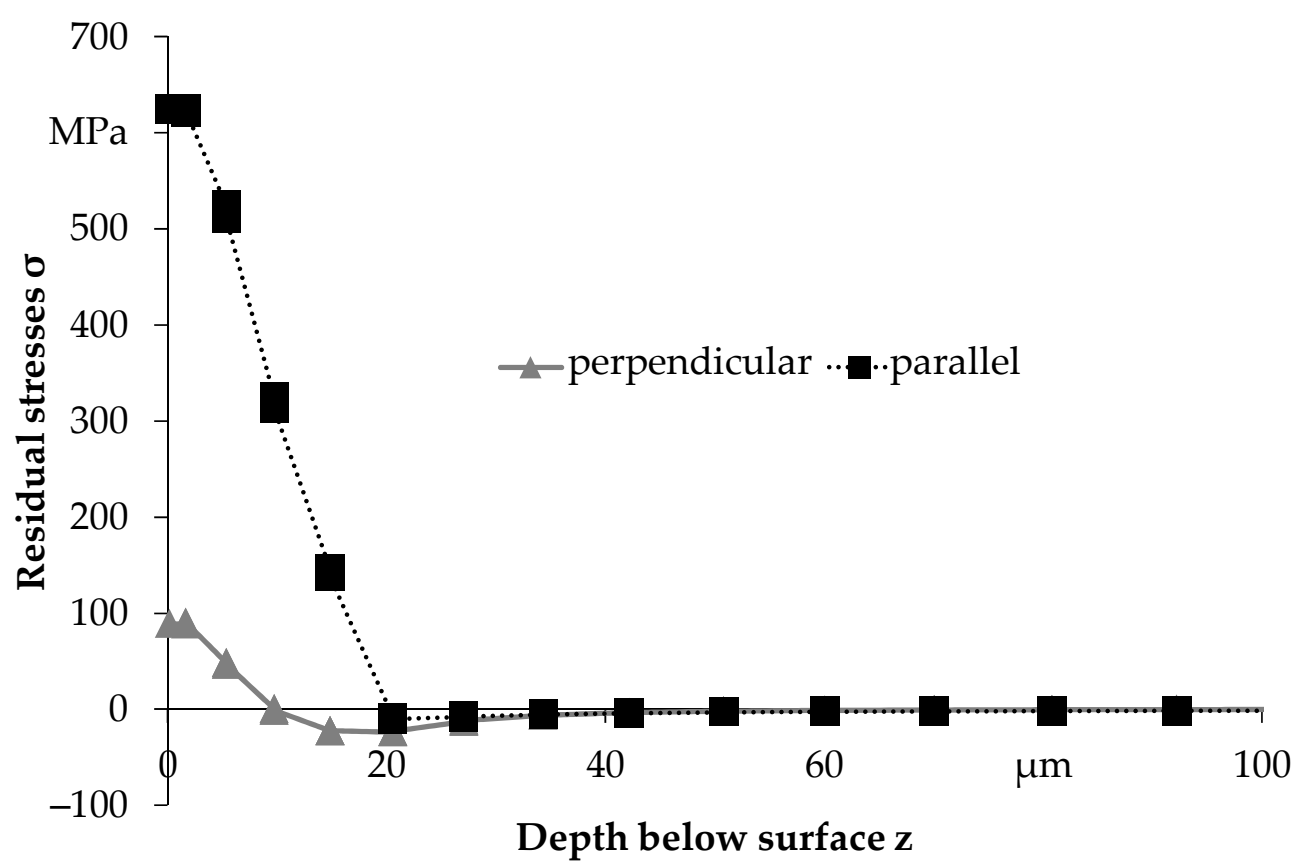

Figure 8. Numerically assessed residual stresses parallel and perpendicular to rolling direction caused by laser heating $\left(\mathrm{F}_{\mathrm{r}}=0 \mathrm{~N} ; \mathrm{P}_{\mathrm{L}}=750 \mathrm{~W} ; \mathrm{v}_{\mathrm{cW}}=7.28 \mathrm{~m} / \mathrm{min}\right) ;$ available in Supplementary Material Residual Stress Data.

The results of the residual stress measurements perpendicular to the rolling direction show an optimum range for surface temperature of $330^{\circ} \mathrm{C}$. A reduction in yield strength at these temperature allows increased plastic deformation, resulting in higher compressive residual stresses. At elevated temperatures, thermally induced dislocation motion is possible, leading to reorientation and annihilation of dislocations and finally relaxation of stresses in the workpiece. If the tempering temperature is considered at which the heat treatment was performed, it becomes clear that in the experiments with $\mathrm{T}_{\mathrm{S}, \max }=450{ }^{\circ} \mathrm{C}$, $600{ }^{\circ} \mathrm{C}$ and $750{ }^{\circ} \mathrm{C}$ the tempering temperature of $400^{\circ} \mathrm{C}$ is exceeded, leading to a continuation of the tempering process. This mechanism also leads to a reduction in residual compressive stresses throughout the depth of the workpiece.

Referring to the approach by Brinksmeier et al. mentioned in the introduction, the obtained results can be used to create specific Process Signatures considering the thermal internal material load (maximal temperature gradient) and its dependency of the mechanical load during the deep rolling process (Figure 9). It becomes obvious that the two directions in which the residual stresses are analysed are influenced by the geometry of the laser optics, and thus the residual stresses perpendicular to the rolling direction are much more influenced by the mechanical stress and an interesting reversal point can be seen in the introduction of residual stresses.

The thermal influence on the residual stresses becomes apparent when considering the depth profiles of the residual stresses perpendicular to the rolling direction depending on the loads due to the thermal effect. At constant mechanical load and an increase of the thermal load, there is an increase of the compressive residual stresses before a further increase of the stress due to the thermal load leads to a shift of the residual stresses towards tension. The cause of the increase in compressive residual stresses can be assumed to be the reduction of the yield strength as a result of the increased stress due to the thermal load, which results in greater plastic deformation and thus a higher mechanical process effect for an identical deep rolling force. An increasing stress due to the thermal load over the laser power $\mathrm{P}_{\mathrm{L}}$, on the other hand, leads to a reduction of the residual compressive stresses at the surface due to the associated dislocation rearrangement and annihilation.

The correlations shown in Figure 9 for the quenched and tempered (QT) and additionally for the ferritic/pearlitic (FP) microstructure indicates that the slope of the curves in 
case of the surface residual stresses parallel to the rolling direction differ. It is clear from this diagram that the use of different maximum temperature gradients in the FP structure has a smaller effect on the propagation of the residual surface stresses than for a quenched and tempered state. This can be explained by the different thermal conductivities and yield strengths of the two heat treatment states.

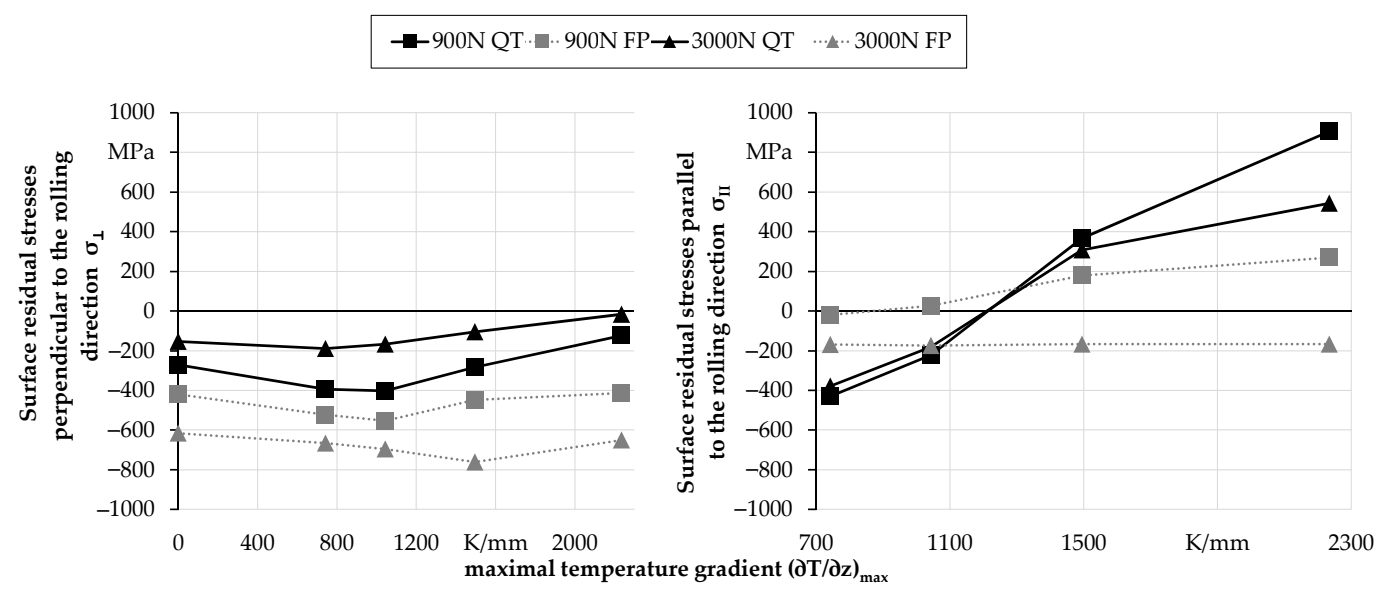

Figure 9. Process Signature for the laser-combined deep rolling process.

\section{Conclusions}

The presented experimental results indicate that a wide range of residual stress profiles can be achieved by using a laser for the introduction of residual stresses during deep rolling. Up to a temperature of $330^{\circ} \mathrm{C}$, the compressive residual stresses perpendicular to the rolling direction can be further increased compared to conventional deep rolling. However, if the temperature is increased, the effect of stress relaxation increases and the residual stress profiles are shifted in the tensile direction.

Based on the findings presented in this work, the positive effect on the yield strength is to be used specifically in future investigations to adjust residual stress depth profiles in a targeted manner. For this purpose, experimental work is to be carried out using temperatures below the critical temperature of approx. $330{ }^{\circ} \mathrm{C}$ and different temperature gradients, thus modifying the material properties to different depths.

In addition, a process signature component for the laser-combined deep rolling process was established within the context of this paper. This procedure represents the first step towards being able to describe all thermo-mechanical processes in this way in the future and thus to predict the resulting modifications based entirely on the prevailing loads during the process. With the help of laser-combined deep rolling, it will also be possible in future work to better understand the interactions between the mechanical and thermal loads and to use this knowledge for all other thermo-mechanical processes.

Supplementary Materials: The following are available online at https:/ / www.mdpi.com/article/ 10.3390/jmmp5020055/s1. Roughness Data: Roughness values for Figure 2. Residual Stress Data: Residual Stresses of Figures $4-8$ as recorded.

Author Contributions: Conceptualization, R.Z.; methodology, R.Z.; software, R.Z.; validation, R.Z.; formal analysis, R.Z.; investigation, R.Z.; resources, D.M.; data curation, R.Z.; writing—original draft preparation, R.Z.; writing—review and editing, D.M.; visualization, R.Z.; supervision, D.M.; project administration, D.M.; funding acquisition, D.M. Both authors have read and agreed to the published version of the manuscript.

Funding: The authors thank the German Research Foundation (DFG) for funding the transregional Collaborative Research Centre "Process Signatures"—Project number 223500200_SFB/TRR 136, sub-project F06. Website: http:/ / www.prozesssignaturen.de/en/home/ accessed on 28 May 2021. 
Data Availability Statement: The data presented in this paper are available in partial in the Supplementary Materials. Additional data for this paper can be obtained from the corresponding author upon request.

Acknowledgments: The authors want to acknowledge their colleague Heiner Meyer, who carried out the residual stress measurements and their colleagues from the sub-project F07 and the bias $\mathrm{GmbH}$ for their technical support with the experimental setup.

Conflicts of Interest: The authors declare no conflict of interest.

\section{References}

1. Jawahir, I.S.; Brinksmeier, E.M.; Saoubi, R.; Aspinwall, D.K.; Outeiro, J.C.; Meyer, D.; Umbrello, D.; Jayal, A.D. Surface integrity in material removal processes: Recent advances. CIRP Ann. Manuf. Technol. 2011, 60, 603-626. [CrossRef]

2. Brinksmeier, E.; Reese, S.; Klink, A.; Langenhorst, L.; Lübben, T.; Meinke, M.; Meyer, D.; Riemer, O.; Sölter, J. Underlying Mechanisms for Developing Process Signatures in Manufacturing. Nanomanuf. Metrol. 2018, 1, 193-208. [CrossRef]

3. Brinksmeier, E.; Klocke, F.; Lucca, D.A.; Sölter, J.; Meyer, D. Process Signatures-A new Approach to Solve the Inverse Surface Integrity Problem in Machining Processes. Procedia CIRP 2014, 13, 429-434. [CrossRef]

4. Brinksmeier, E.; Meyer, D.; Heinzel, C.; Lübben, T.; Sölter, J.; Langenhorst, L.; Frerichs, F.; Kämmler, J.; Kohls, E.; Kuschel, S. Process Signatures-Missing Link to Predict Surface Integrity in Machining. Procedia CIRP 2018, 71, 3-10. [CrossRef]

5. Kämmler, J.; Wielki, N.; Meyer, D. Surface integrity after internal load oriented multistage contact deep rolling. Procedia CIRP 2018, 71, 490-495. [CrossRef]

6. Frerichs, F.; Sölter, J.; Lübben, T.; Brinksmeier, E.; Zoch, H.-W. A simulation based development of Process Signatures for manufacturing processes with thermal loads. Procedia CIRP 2016, 45, 327-330. [CrossRef]

7. Kohls, E.; Zmich, R.; Heinzel, C.; Meyer, D. Residual stress change in multistage grinding. Procedia CIRP 2020, 87, 186-191. [CrossRef]

8. Schulze, V. Modern echanical Surface Treatment: States, Stability, Effects; Wiley-VCH: Hoboken, NJ, USA, 2005.

9. Schulze, V.; Bleicher, F.; Groche, P.; Guo, Y.B.; Pyun, Y. Surface modification by machine hammer peening and burnishing. CIRP Ann. Manuf. Technol. 2016, 65, 809-832. [CrossRef]

10. Kwang-Sun, K.; Jae-Hyun, K.; Jun-Young, C.; Choon-Man, L. A Review on Research and Development of Laser Assisted Turning. Int. J. Precis. Eng. Manuf. 2011, 12, 753-759.

11. Wang, Y.; Yang, L.J.; Wang, N.J. An investigation of laser-assisted machining of Al2O3 particle reinforced aluminum matrix composite. J. Mater. Process. Technol. 2002, 129, 268-274. [CrossRef]

12. Anderson, M.C.; Shin, Y.C. Laser-assisted machining of an austenitic stainless steel: P550. J. Eng. Manuf. 2006, 220 , 2055-2067. [CrossRef]

13. Brecher, C.; Emonts, M.; Rosen, C.J.; Hermani, J.P. Laser-assisted Milling of Advanced Materials. Phys. Procedia 2011, 12, 599-606. [CrossRef]

14. Mening, R.; Schulze, V.; Vöhringer, O. Optimized warm peening of the quenched and tempered steel AISI 4140. Mater. Sci. Eng. A335 2002, 335, 198-206. [CrossRef]

15. Wick, A.; Schulze, V.; Vöhringer, O. Effects of warm peening on fatigue life and relaxation behaviour of residual stresses in AISI 4140 steel. Mater. Sci. Eng. A293 2000, 293, 191-197. [CrossRef]

16. Klocke, F.; Brummer, C.M. Laser-assisted metal spinning of challenging materials. Procedia Eng. 2014, 81, 2385-2390. [CrossRef]

17. Maier, B. Beitrag zur thermischen Prozessmodellierung des Schleifens. Ph.D Thesis, WZL RWTH Aachen, Aachen, Germany, 2008.

18. Cherif, A.; Scholtes, B. Kombinierte thermische und mechanische Festwalzbehandlungen von gehärtetem und vergütetem Stahl Ck 45*. Z. Werkst. Wärmebeh. Fert. 2008, 63, 155-160. [CrossRef]

19. Eigenmann, B.; Macherauch, E. Röntgenographische Untersuchung von Spannungszuständen in Werkstoffen. Mater. Werkst. 1995, 26, 148-160. [CrossRef]

20. Noyan, I.C.; Huang, T.C.; York, B.R. Residual Stress/Strain Analysis in Thin Films by X-Ray Diffraction. Crit. Rev. Solid State Mater. Sci. 1999, 20, 125-177. [CrossRef] 